Research Article

\title{
Fusion Mode and Style Based on Artificial Intelligence and Clothing Design
}

\author{
Jiali Qiu' ${ }^{1}$ and Lianghua $M a \mathbb{D}^{2}$ \\ ${ }^{1}$ School of Arts and Humanities, Hunan International Economics University, Changsha 410205, Hunan, China \\ ${ }^{2}$ School of Fine Arts Education, Guangzhou Academy of Fine Arts, Guangzhou 510000, Guangdong, China \\ Correspondence should be addressed to Lianghua Ma; malianghua@gzarts.edu.cn
}

Received 11 August 2021; Revised 24 September 2021; Accepted 5 October 2021; Published 10 November 2021

Academic Editor: Sang-Bing Tsai

Copyright ( 2021 Jiali Qiu and Lianghua Ma. This is an open access article distributed under the Creative Commons Attribution License, which permits unrestricted use, distribution, and reproduction in any medium, provided the original work is properly cited.

\begin{abstract}
With the upgrading of intelligent manufacturing, industrial robots will play an important role in the garment industry. The purpose of this article was to study the pattern and style based on the integration of artificial intelligence and clothing design. In this article, the digital modeling of clothing design and the case analysis of intelligent clothing design are described using the method of comparative experiment. The experimental results are obtained from the analysis of fuzzy number of clothing design language evaluation, three-dimensional human body construction clothing size, clothing design elements and auxiliary functions, and the analysis of the advantages and disadvantages of clothing design system. The popular clothing sample is D4 (0.4862), which is $20 \%$ higher than other products. It can be concluded that the model proposed in this article can grasp the needs of consumers and select the right one according to the market positioning. The fabric mass production fashion brand can significantly improve the efficiency and satisfaction of the fabric selection decision-making process. It provides enough technical support and style model for intelligent clothing design.
\end{abstract}

\section{Introduction}

China's clothing industry is a traditional industry with a low degree of modernization. Most of clothing design is still in the stage of manual design. Compared with foreign advanced garment enterprises, there is a big gap between design ability and brand effect. In today's digital era, the use of "information technology to promote industrialization" and the application of information technology to the clothing industry have become a hot research topic in the clothing and information industry.

With the progress of science and technology, the combination of human thinking mode and computer technology, and the application of artificial intelligence technology in the design work, make the computer-aided design with the characteristics of human design and thinking to some extent become a new trend in the field of clothing design. The introduction of artificial intelligence plays an important role in reducing the excessive dependence on people in design, improving the randomness of feeling and inspiration in design, adapting to the requirements of fast rhythm and short period in customized design and production, and improving the overall technical level of the clothing industry.

Khare and Varshneya investigated the influence of green clothing knowledge on the past environmental behavior, peer influence, and purchase behavior in the purchase behavior of organic clothing. His design method is to collect data through surveys conducted in three major metropolitan areas and collect 889 samples of college students. His findings show that past environmental actions have affected young people's organic clothing buying behavior. Interestingly, knowledge of green clothes and peer influence will not affect the purchase behavior of organic clothes. The effect of his research limitations is that samples are limited to students with an experience in green products [1]. Through analyzing the development situation and trend in AI design, Yi integrated $\mathrm{AI}$ and fashion design into a large database by 
combining various hardware and software intelligent platforms and made clear that fashion design, character recommendation, and virtual Fitty can achieve bending and other functions. In his artificial intelligence design innovation, he proposed four modes: intelligent assistant design, intelligent copy design, intelligent matching design, and intelligent integrated design. Problems that may be faced by clothing AI design include advocating happiness and comfort, adapting to docking integration, open efficient and safe data security recommendations, promoting the excellent development of clothing in AI design, and referring to clothing design and AI researchers to provide [2].

This article explains the style factor decomposition and fabric factor decomposition of clothing design and then shows the digital modeling of clothing design, fuzzy number correlation technology. Then, it shows the case analysis of intelligent clothing design reasonably, such as the analysis of the advantages and disadvantages of clothing design system, clothing design, and the necessity of integrating clothing into artificial intelligence technology. Design elements and auxiliary function analysis and digital design-3d printing technology together with analysis and demonstration of the research results add value to the significance of clothing design style under artificial intelligence.

\section{Fashion Design Fusion Style}

2.1. Decomposition of Fashion Design Elements. Clothing style design refers to the design of the external outline and internal details of clothing. Different types of clothing have different shapes and design points $[3,4]$.

2.1.1. External Profile. The outline of clothes is also called outline and modeling line, which refers to the outline of the outer modeling of clothes. It is the root of the overall appearance and shape of the abstracted clothes. The appearance of the clothes is different from the local details, attracting people's eyes and giving people a good first impression. Different external outlines can not only show the style and popular features of clothes but also reflect the temperament and character of the wearer.

People are the carrier of clothes. Clothes must be designed according to human body structure. Therefore, the change of clothing shape is mainly realized by the change of shoulder, waist, waist, and hem $[5,6]$.

2.1.2. Interior Details. The details inside the clothes are usually the structural elements outside the frame, including collar, sleeve, pocket, front stand, side swing, split line, local road, pleats, stitches, back seams, cuffs, decorative arts, and crafts. By carefully designing these local details, not only the function of the clothes can be improved but also the beauty of various shapes of the clothes can be reflected $[7,8]$.

(1) Collar. Collar is an important part of the elements of man's suits. Its position is easy to become the focus of vision, and to a certain extent, it becomes the popularity center of man's suits. According to its different structure, it can be summarized as follows: collarless, vertical collar, pleated collar, flat collar, barbed collar, lapel, and the like.

(2) Placket. The design of detail elements of man's wear is also reflected in the design of the placket, with the emphasis on the opening and closing design of the placket and the modeling of the front dress. The outer edge of the front door flap is related to the opening of the collar and the overall style of the suit to a certain extent: the collar has a large opening and a small number of buttons, which can be matched by a large circle pendulum; the collar has a small opening and a large number of buttons, which can be matched by a sharp angle or a rounded hem. Therefore, there are three forms of the front door flap outer edge hem design: sharp corner, wipe round corner, and large round corner $[9,10]$.

(3) Pocket. Pocket is another important style element of clothes and a language of fashion atmosphere. It plays a role as a theme song.

The main appearance of man's top is chest pocket. The small pocket of the coat is called "towel bag." Fold up the flat decorative towel to expose the small edge, and one can match the overall color. In addition, in order to maintain the gentlemanly style, it is not suitable to put other things. There are only light and thin things on the waist. Like the refutation of the head, the male pocket lost its original function for a long time, evolved into a stylized design, and clarified the history and culture of the male clothing with potential effects. The shape and angle of the towel bag in chess will be influenced by fashion, but the most popular basic shape is the bow shape with large and wide corners, the round shape with clear lines at both ends and small corners, and the basic shape of the isosceles pocket, such as the patch bag and the waist bag (digging bag) with drilling bag. The key points of the design are the position of the package, the treatment of the angle of the package, whether there is a glow line and whether there is a cover. To sum up, there are three types of art forms in the chest and waist pocket: digging bag, sticking bag, and no bag $[11,12]$.

(4) Decoration Technology. Clothing decoration technology is mainly divided into two categories. Its line and traditional rolling decoration. Among them, the seized thread can adopt the shape of traditional manual sewing, the color of the thread is generally the same as that of the cloth, and the quilting method is adopted. There is also a simple flat cover for sewing machines. In general, satin materials are widely used, and the color and texture are the same color, but the contrast and texture of brightness and color are different, resulting in a variety of visual effects, reaching a rich design goal $[13,14]$.

\subsection{Decomposition of Fabric Elements in Clothing Design}

2.2.1. Apparent Characteristics. Material has two parts: material and texture. In the case of cloth, material refers to the material type of cloth, and texture refers to the texture structure and characteristics formed by the weaving of fiber 
and thread. Due to its excellent stability, warmth, wear resistance, and the continuous development of current processing technology, it overcomes the shortcomings of natural fibers, such as wrinkles and shrinkage, but it has been more and more generally accepted. Generally speaking, it is leisure in daily life. This kind of fabric is similar to the natural fiber with pure texture and touch, and it has excellent wrinkle resistance and shrinkage resistance. It has a distinctive appearance and excellent firmness, and its price is cheaper than that of pure natural fiber $[15,16]$.

2.2.2. Pattern. For the appearance characteristics of fabric, material is not the only factor, and the pattern change of fabric surface will also have a specific impact on the visual style and purpose of fabric. The stripe pattern fabric and the city pine pattern fabric strengthen the visual charm of the lines. By adjusting the spacing of the stripes, the mesh size, and the weight of the clothes, the emphasis on the horizontal direction and the vertical direction is visually emphasized. The texture of the dot pattern, according to the size of the dot, the contrast between the dot pattern and the color of the cloth, produces unexpected visual effects. The design of man's clothing is generally used as a supplement to neckties and other decorations and clothing $[17,18]$.

Therefore, the pattern elements are divided into nine categories: plain color, stripe, grid, and pattern.

2.2.3. Intrinsic Characteristics. The realization of garment appearance modeling has a very important relationship with the inherent characteristics of fabric, and the returning, drawing, pushing, sewing, and shrinking in the process of garment making will also have a certain impact on the appearance modeling of clothing. The essence of these influences is the embodiment of the inherent properties of fabrics $[19,20]$.

2.3. Digital Modeling of Clothing Design. In order to formalize and model human perception data, several intelligent technologies are selected, including fuzzy technology, fuzzy analysis hierarchy process, TOPSIS, and case-based reasoning. Firstly, we introduce the concepts of fuzzy set, fuzzy relation, and correlation operation, that is, to be able to deal with the process of fuzzy and uncertain human perception data obtained in sensory evaluation. Based on these basic concepts, two classical sorting and clustering methods are proposed, namely, fuzzy AHP and fuzzy TOPSIS. Using fuzzy analytic hierarchy process to model the knowledge structure in clothing recommendation, fuzzy TOPSIS is a data analysis tool, which is used for global decision-making based on different mathematical models [21, 22].

2.3.1. Fuzzy Theory and Related Technology. The whole real world is complex, and complexity comes from fuzziness. If the complexity of a problem exceeds a certain threshold, the system must become fuzzy and natural.
2.3.2. Classical Set Theory. A collection is defined by a simple statement that describes whether a particular element has an attribute that belongs to that particular collection. Classical set theory enumerates the use of $a=\left\{a_{1}, a_{2}, a_{3}\right.$ Element of, $\left.a_{n}\right\}$. If the element $a I$ (I belongs to $\{1,2,3, \ldots, N\}$ ) is a subset of the universal set $X$, then the set a can be represented as all the elements $X$.

$$
\mu_{A}= \begin{cases}1, & x \in X, \\ 0, & \text { otherwise. }\end{cases}
$$

2.3.3. Standard Operation of Fuzzy Set. The membership function of complement fuzzy set a is defined as follows:

$$
U_{\bar{A}}(x)=1-U_{A}(x), \quad \forall x \in X .
$$

The relationship value of element $X$ in the union takes the membership degree corresponding to $a$ and $B$ :

$$
U_{A \cup B}(x)=\operatorname{Max}\left[U_{A}(x), U_{B}(x)\right], \quad \forall x \in X .
$$

The membership function of intersection of two fuzzy sets $A$ and $B$ takes the smaller value $A \cup B=B \cup A$ of $A$ and $B$,

$$
U(A \cap B)(x)=\operatorname{Min}\left[U_{A}(x), U_{B}(x)\right], \quad \forall x=X .
$$

2.3.4. Properties of Fuzzy Sets. Considering the properties of three fuzzy sets $a, B$, and $C$ defined on domain $x$, classical sets are also suitable for fuzzy sets. They include the following:

Exchange ability:

$$
\begin{aligned}
& A \cap B=B \cap A, \\
& A \cup B=B \cup A .
\end{aligned}
$$

Binding:

$$
\begin{aligned}
A \cup(B \cup C) & =(A \cup B) \cup C, \\
A \cap(B \cap C) & =(A \cap B) \cap C, \\
A \cup \varphi & =A, \\
A \cap X & =A, \\
A \cap \varphi & =\varphi, \\
A \cup X & =X .
\end{aligned}
$$

2.3.5. Triangular Fuzzy Number. Triangular fuzzy number (TFN) is one of the most commonly used fuzzy numbers. A TFN is usually expressed as $M=(L, m, U)$ or $M=(\mathrm{L}|m, m| U)$ in $n$-tuple form, where $l, m$, and $u$ represent the minimum possible value, the maximum possible value, and the maximum possible value of fuzzy event, respectively. A set of TFN can be defined as follows: 


$$
\begin{aligned}
& \mu(x)=0, \quad x \in[-\infty, l] \cup x \in[u,+\infty], \\
& \mu(x)=\frac{x-l}{m-l}, \quad x \in[l, m], \\
& \mu(x)=\frac{x-u}{m-u}, \quad x \in[m, u] .
\end{aligned}
$$

2.3.6. Similarity Measurement. Euclidean distance can be used to describe the distance between two TNF. The distance between $M_{1}=\left(l_{1}, m_{1}, u_{1}\right)$ and $M_{2}=\left(l_{2}, m_{2}, u_{2}\right)$ can be expressed as follows:

$$
d\left(M_{1}, M_{2}\right)=\sqrt{\frac{1}{3}\left[\left(l_{1}-l_{2}\right)^{2}+\left(m_{1}-m_{2}\right)^{2}+\left(u_{1}-u_{2}\right)^{2}\right.} .
$$

Based on the above equation, the similarity of $M_{1}=\left(l_{1}, m_{1}\right.$, $\left.u_{1}\right)$ and $M_{2}=\left(l_{2}, m_{2}, u_{2}\right)$ of two different TFNs can be expressed as follows:

$$
\begin{aligned}
S\left(M_{1}, M_{2}\right) & =1-d\left(M_{1}, M_{2}\right) \\
& =1-\frac{1}{10} \sqrt{\frac{1}{3}\left[\left(n_{1}-m_{1}\right)^{2}+\left(n_{2}-m_{2}\right)^{2}+\left(n_{3}-m_{3}\right)^{2}\right]} .
\end{aligned}
$$

2.3.7. PCA-Based Dimensionality Reduction Technology. Traditional linear principal component analysis can effectively deal with the linear relationship between variables, but in reality, many data are nonlinear, and linear principal component analysis cannot detect the nonlinear structure between the data. In particular, kernel principal component analysis can not only extract the nonlinear features of the data but also the calculation of its nonlinear principal components is simple (solving eigenvalue problems) and has clear meaning (linear principal components in the feature space), so it is widely used in many fields. Principal component analysis calculation steps:

(1) Calculate the correlation coefficient matrix

$$
R=\left[\begin{array}{cccc}
r_{11} & r_{12} & \cdots & r_{1 p} \\
r_{21} & r_{22} & \cdots & r_{2 p} \\
\vdots & \vdots & \vdots & \vdots \\
r_{p 1} & r_{p 2} & \cdots & r_{p p}
\end{array}\right] .
$$

In formula (11), $r_{i j}(i, j=1,2, \ldots, p)$ is the correlation coefficient between $x_{i}$ and $x_{j}$ of the original variable, and the calculation formula is given by

$$
r_{i j}=\frac{\sum_{k=1}^{n}\left(x_{k i}-\bar{x}_{i}\right)\left(x_{k j}-\bar{x}_{j}\right)}{\sqrt{\sum_{k=1}^{n}\left(x_{k i}-\bar{x}_{i}\right)^{2} \sum_{k=1}^{n}\left(x_{k j}-\bar{x}_{j}\right)^{2}}} .
$$

Because $R$ is a real symmetric matrix, you only need to calculate the upper or lower triangular elements.
(2) Calculate eigenvalues and eigenvectors

First solve the characteristic equation $|\lambda I-R|=0$, usually use the Jacobian method to find the characteristic value $\lambda_{i}(i=1,2, \ldots, p)$, and arrange it in order of magnitude and then calculate the characteristic vector $e_{i}(i=1,2, \ldots, p)$ corresponding to the characteristic value $\lambda_{i}$, respectively. Here requires $\left\|e_{i}\right\|=1$, where $e_{i j}$ represents the $j$ component of the vector $e_{i}$.

(3) Calculate principal component contribution rate and cumulative contribution rate

The contribution rate of principal component $z_{i}$ :

$$
\frac{\lambda_{i}}{\sum_{k=1}^{p} \lambda_{k}} \quad(i=1,2, \ldots, p) \text {. }
$$

Cumulative contribution rate:

$$
\frac{\sum_{k=1}^{i} \lambda_{k}}{\sum_{k=1}^{p} \lambda_{k}} \quad(i=1,2, \ldots, p) \text {. }
$$

Generally, the first, second, ..., $m(m \leq p)$ principal components corresponding to the characteristic value $\lambda_{1}, \lambda_{2}, \ldots, \lambda_{m}$ with a cumulative contribution rate of $85-95 \%$ are taken.

(4) Calculate the principal component loading

The calculation formula is

$$
I_{i j}=p\left(z_{i}, x_{j}\right)=\sqrt{\lambda_{i}} e_{i j} \quad(i, j=1,2, \ldots, p)
$$

After getting the load of each principal component, one can further calculate to get the score of each principal component:

$$
Z=\left[\begin{array}{cccc}
z_{11} & z_{12} & \cdots & z_{1 m} \\
z_{21} & z_{22} & \cdots & z_{2 m} \\
\vdots & \vdots & \ddots & \vdots \\
z_{n 1} & z_{n 2} & \cdots & z_{n m}
\end{array}\right] .
$$

2.4. Necessity of Integrating Artificial Intelligence Technology. The pattern of clothing design based on digital network is clear in two aspects and needs further improvement. Research and development of design accuracy and product customization. At present, R \& D design is mainly based on the interaction between customers and designers. On the one hand, designers make design plans based on experience. Because of the deviation of designers' ability, design plans sometimes cannot meet the needs of customers' customization. On the other hand, whether the customized products have manufacturing conditions is also based on the designer's design. According to personal judgment, the creativity and personalization of customized products are limited to a certain extent. In order to achieve the high efficiency and precision of customized product development and design, more complex multidimensional data and more 
efficient data processing and data mining technologies are combined $[23,24]$.

The identification possibility of clothing products is a process condition to meet the needs of customers. There is room for further decomposition of general production modules of different styles of products. The existing digital network technology has not effectively solved the processing optimization of more complex and diverse production modules. In the manufacturing process, we also need to strengthen the effective use of resources and energy. Based on the digital network technology, automatic production scheduling can be realized, and the production scheduling mode and method need to be updated under more complex production conditions [25].

\section{Intelligent Clothing Design with Case Analysis}

3.1. Fuzzy Number of Clothing Design Language Evaluation. The language rating scale used at this stage is extremely more important, more important, a little more important, equal, a little less important, less important and extremely less important. Then there are two evaluation criteria (main evaluation criteria and subevaluation criteria) about the internal relative importance of pairwise comparison matrix, which are converted to trigonometric fuzzy number (TFN) and further processed using the fuzzy set tool (Table 1 for details).

Two levels of evaluation criteria will be obtained and standardized. The final importance level of the secondary evaluation criteria (fabric properties) is weighted according to their highest evaluation criteria (consumer requirements). The latter normalization process, the normalization importance level of sub valuation criteria, can be obtained. These fabric properties will be further used to evaluate the performance of alternative fabrics as shown in Table 2:

As shown in Figure 1, it can be seen that if the gray value of the clothing image with printed patterns is similar to the background, the contour extraction will encounter a lot of texture noise problems. A new processing technique is proposed: the initial contour is extracted by the morphological method. Design a fulcrum, divide the contour into a number of single-value branches, use the contour error calculation to identify, and eliminate the texture noise on the branches.

3.2. Garment Size of 3D Human Body Construction. The data required by the automatic generation system of man's clothing pattern is provided by the three-dimensional anthropometric system, and the relationship between the size data required by the pattern and the measured data is shown in Table 3.

Select the measured data according to the above table and convert the existing data to obtain the required size of the paper pattern generation through the relational conversion, which is the parameter data that must be input in the paper pattern generation system. As for the gap, this
TABLE 1: Language assessment scale and corresponding fuzzy number.

\begin{tabular}{lc}
\hline Linguistic values & TFNs \\
\hline Extremely more important (EMI) & $(3.5,4,4.5)$ \\
More important (MI) & $(3,3.5,4)$ \\
A little more important (AMI) & $(2.5,3,3.5)$ \\
Equal (E) & $(2,2.5,3)$ \\
A little less important (ALI) & $(1.5,2,2.5)$ \\
Less important (LI) & $(1,1.5,2)$ \\
Extremely less important (ELI) & $(0.5,1,1.5)$ \\
\hline
\end{tabular}

TABle 2: Data sheet for appraisal of fashion design language.

\begin{tabular}{lccccccc}
\hline D-samples & EMI & MI & AMI & $E$ & ALI & LI & ELI \\
\hline D1 & 2.16 & 2.41 & 2.3 & 2.41 & 2.67 & 3.45 & 3.48 \\
D2 & 2.9 & 2.84 & 3.05 & 3.45 & 2.86 & 3.88 & 4.14 \\
D3 & 2.95 & 3.18 & 4.49 & 4.06 & 4.03 & 4.98 & 4.94 \\
D4 & 4.26 & 4.43 & 4.98 & 4.89 & 4.91 & 5.18 & 5.23 \\
D5 & 4.86 & 4.99 & 5.33 & 4.83 & 5.12 & 7.47 & 6.82 \\
\hline
\end{tabular}

study used the existing national standard size to determine the relationship between the gap, on the basis of the motherboard, using the existing position gap to determine other size patterns.

\subsection{Clothing Design Elements and Auxiliary Functions}

3.3.1. Analysis of Fashion Design Elements. Figure 2 is the analysis diagram of clothing design elements.

As shown in Figure 2, when people choose satisfactory clothing, problems often lead to the formalization of design standards or requirements in the process of clothing design. In order to design the clothing suitable for this crowd, the relationship elements between the clothing design and these design standards will be established.

3.3.2. Accessibility Analysis. The auxiliary function of clothing is also crucial. Table 4 shows the specific fashion requirements and corresponding proportions of auxiliary tools. We draw a histogram based on this result, as shown in Figure 3.

Figure 3 shows the specific fashion requirements of auxiliary tools. For clothing design, some special auxiliary tools with different fabric characteristics are really needed. $55 \%$ of them think "water management" is very important, $36 \%$ of them think "sweat absorption" is very important, $33 \%$ of them vote for "wear resistance," $29 \%$ of them are "easy to clean," and $21 \%$ of them are "wrinkle free."

\subsubsection{Analysis of the Relationship between Clothing Design} Elements and Auxiliary Functions. The relationship between clothing design elements and auxiliary functions is also very important. Table 5 lists the relationship between clothing design elements and auxiliary functions. We draw a bar graph based on this result, as shown in Figure 4. 


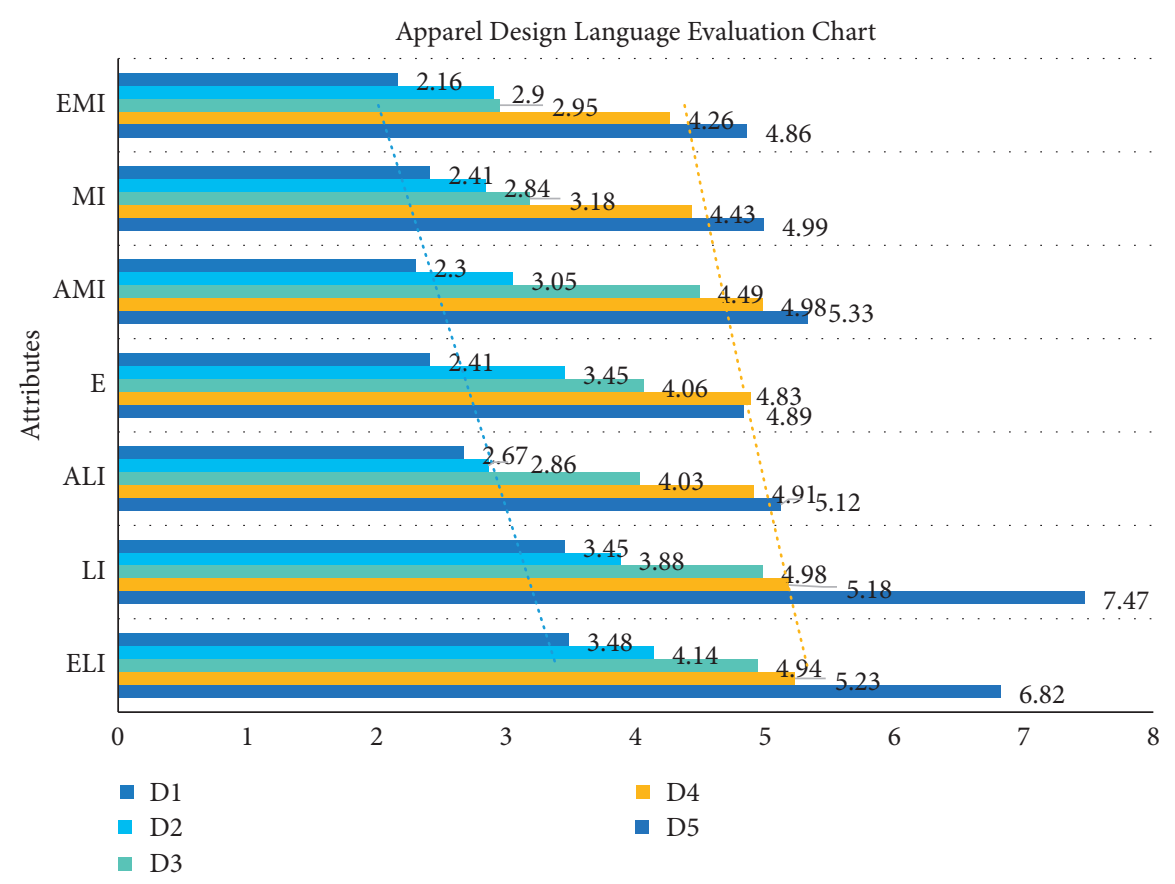

Figure 1: Apparel design language evaluation chart.

TABLE 3: Relationship between parts and measured dimensions.

Bust

Dorsal length

The waist

Hipline

Superior femoral length

Patella line

Wide waistband

Pant length

\section{Chest line}

Sitting position: high cervical point, high waist circumference Waistline, front waistline, back waistline

Front abdominal circumference, rear hip circumference Waist height

Front knee circumference, rear knee circumference Ankle circumference Sitting cervical point height

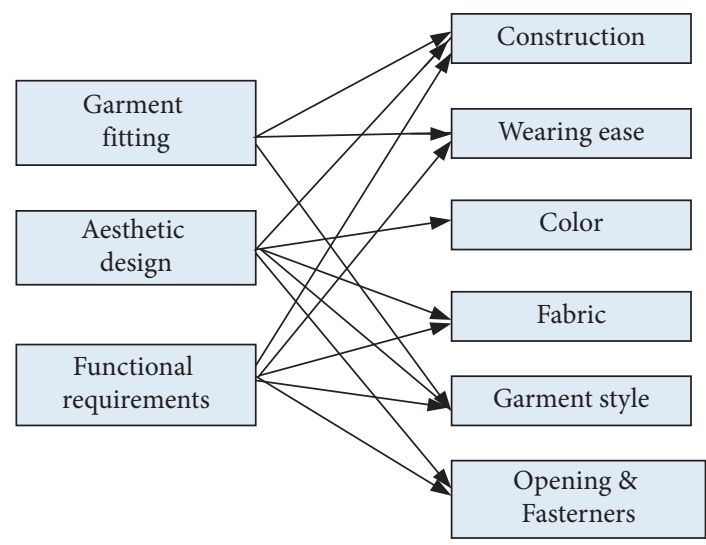

Figure 2: Analysis of clothing design elements.

Figure 4 shows the relationship analysis between clothing design elements and auxiliary functions. For clothing design, some special auxiliary tools with different fabric characteristics are really needed. $26 \%$ of them think "construction" is very important, $12 \%$ of them think "wearing ease" is very important, $13 \%$ of them vote
TABle 4: Specific fashion requirements data sheet for auxiliary tools.

\begin{tabular}{lcc}
\hline & Specific fashion requirements & Proportion (\%) \\
\hline \multirow{4}{*}{ Tools } & Water management & 24 \\
& Sweat absorption & 13 \\
& Wear resistance & 16 \\
& Easy to clean & 12 \\
& Wrinkle free & 9 \\
\hline \multirow{4}{*}{ Auxiliary tools } & Water management & 31 \\
& Sweat absorption & 23 \\
& Wear resistance & 17 \\
& Easy to clean & 17 \\
& Wrinkle free & 12 \\
\hline
\end{tabular}

for "garment style," $14 \%$ of them are "color," $19 \%$ of them are "fabric," and $16 \%$ of them are "opening fasterners."

\subsection{Advantages and Disadvantages of Clothing Design System}

3.4.1. Experimental Design. In the validation experiment, another group of 40 representative consumers also participated. The selection of 40 members was explained. In the verification 


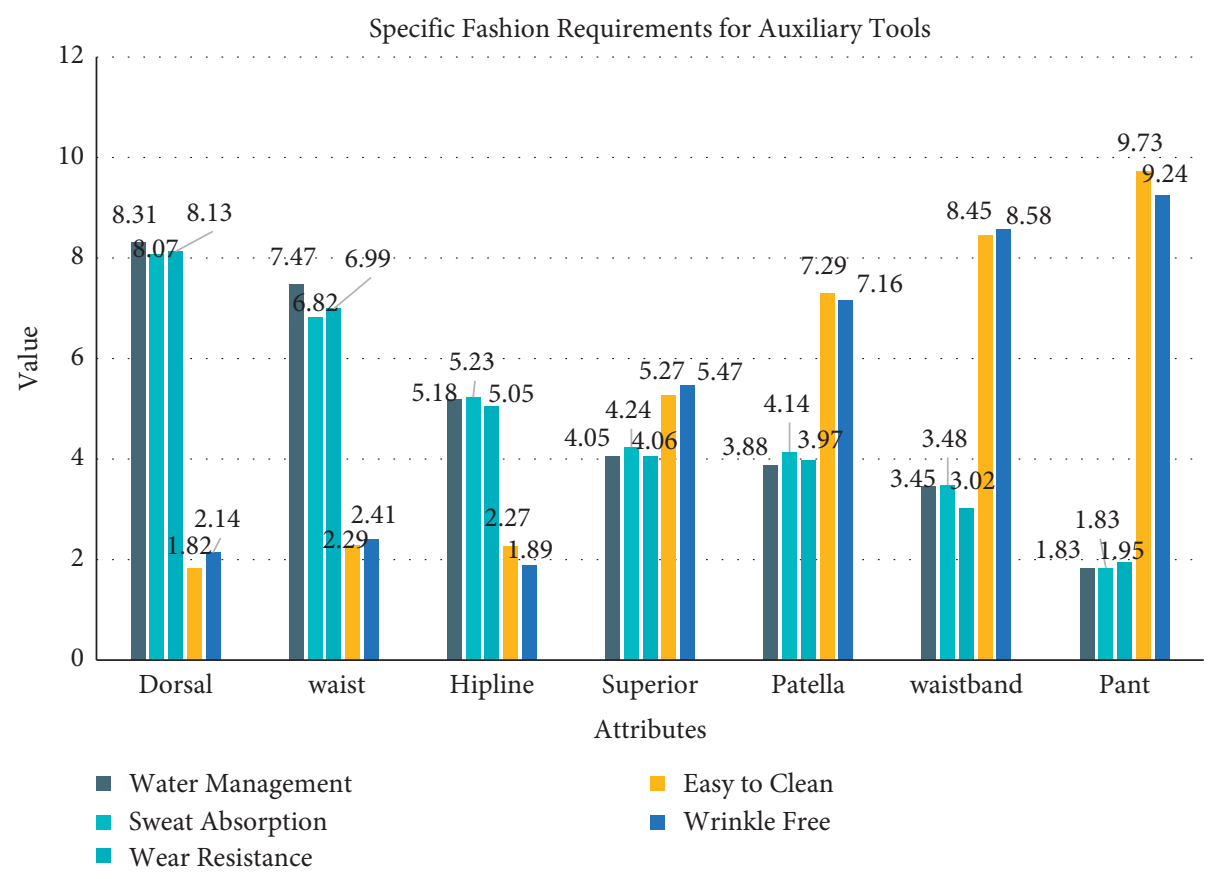

FIGURE 3: Specific fashion requirements of auxiliary tools.

TABLE 5: The relationship data table of clothing design elements and auxiliary functions.

\begin{tabular}{|c|c|c|}
\hline Attributes & Specific fashion requirements & Proportion (\%) \\
\hline \multirow{3}{*}{ Garment fitting } & Construction & 4 \\
\hline & Wearing ease & 3 \\
\hline & Garment style & 6 \\
\hline \multirow{5}{*}{ Aesthetic design } & Construction & 7 \\
\hline & Color & 14 \\
\hline & Fabric & 8 \\
\hline & Garment style & 2 \\
\hline & Opening fasterners & 8 \\
\hline \multirow{5}{*}{ Functional requirements } & Construction & 15 \\
\hline & Wearing ease & 9 \\
\hline & Fabric & 11 \\
\hline & Garment style & 5 \\
\hline & Opening fasterners & 8 \\
\hline
\end{tabular}

experiment, every consumer should give the ranking of all clothing samples. The price information and fabric content information are on the label of each garment. After that, all consumers were assigned to observe and touch the clothes. Then, it gives five evaluation scales from $a$ to $e(a, B, C, D, e)$ based on the overall evaluation of each consumer. " $A$ " means the best of all these clothes, and " $e$ " means the worst of all these clothes. A set of linguistic terms used to describe a performance level. To quantify the degree of evaluation, a set of fuzzy numbers is assigned to each language term. Table 6 provides the degree of evaluation and the corresponding linguistic terms and fuzzy numbers.

3.4.2. Discussion of Results. Using equation, the evaluation results of all evaluators can be summarized. The figure shows the distance from the aggregate evaluation results of each clothing sample to each evaluation degree. These distances represent the subordination degree of each clothing sample to different evaluation levels. A shorter distance indicates a higher degree of membership.

Generally speaking, all clothing samples can be regarded as "best (be)" or "very good (VG)," which indicates that the selected alternative fabrics are in line with the market position of fashion brands in this respect. The invited designers can understand the design position and choose the right fabric according to the market situation. As shown in Table 7, different fabrics produce the same style of clothes. We draw a line chart based on this result, as shown in Figure 5.

As shown in Figure 5, in order to rank the performance of all clothing samples, more attention should be paid to the distance from the "best (be)" evaluation level. In this case, from the shortest to the longest is D4 (0.4862), D5 (0.4962), D3 (0.5393), D2 (0.6452), and D1 (0.836), indicating that the 


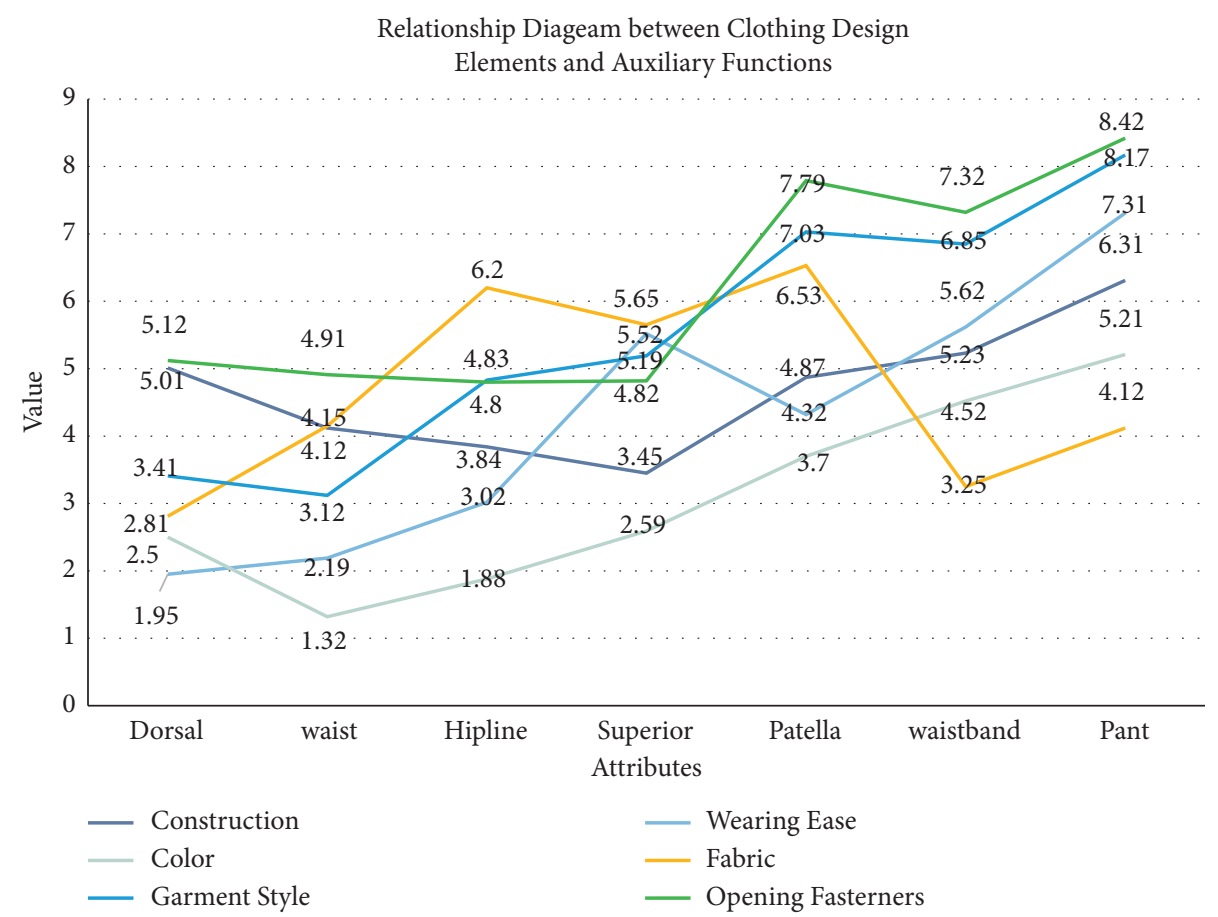

Figure 4: The relationship diagram between clothing design elements and auxiliary functions.

TABLE 6: Evaluation degree and its corresponding language items and fuzzy numbers.

\begin{tabular}{lcc}
\hline Evaluation degrees & Linguistic term & Fuzzy numbers \\
\hline$A$ & Best (BE) & $(2.5,3,3.5)$ \\
$B$ & Relatively good (RG) & $(2,2.5,3)$ \\
$C$ & Average (AV) & $(1.5,2,2.5)$ \\
$D$ & Relatively poor (RP) & $(1,1.5,2)$ \\
$E$ & Worst (WO) & $(0.5,1,1.5)$ \\
\hline
\end{tabular}

TABLE 7: The same style of clothes made of different fabric data sheet.

\begin{tabular}{lccccc}
\hline $\begin{array}{l}\text { Dress } \\
\text { samples }\end{array}$ & Worst & $\begin{array}{c}\text { Relatively } \\
\text { poor }\end{array}$ & Average & $\begin{array}{c}\text { Relatively } \\
\text { good }\end{array}$ & Best \\
\hline D1 & 1.376 & 1.289 & 1.137 & 0.856 & 0.869 \\
D2 & 1.119 & 1.067 & 0.936 & 0.653 & 0.623 \\
D3 & 0.944 & 0.917 & 0.779 & 0.576 & 0.436 \\
D4 & 0.805 & 0.798 & 0.632 & 0.481 & 0.294 \\
D5 & 0.857 & 0.849 & 0.683 & 0.489 & 0.343 \\
\hline
\end{tabular}

popular clothing samples are D4, and the rest are D5, D3, D2, and D1. The result of this ranking fully accords with the selected content from the proposed selection system shows that the proposed model can grasp the needs of consumers and select the appropriate fabric mass production fashion brand according to the market positioning. In addition, the design knowledge of designers can be extracted and applied to the construction of AHP model of interaction process. It can be seen from the experimental results that the proposed system can significantly improve the efficiency and satisfaction of fabric selection decision-making process. The result of the proposed system is true and accurate, and the

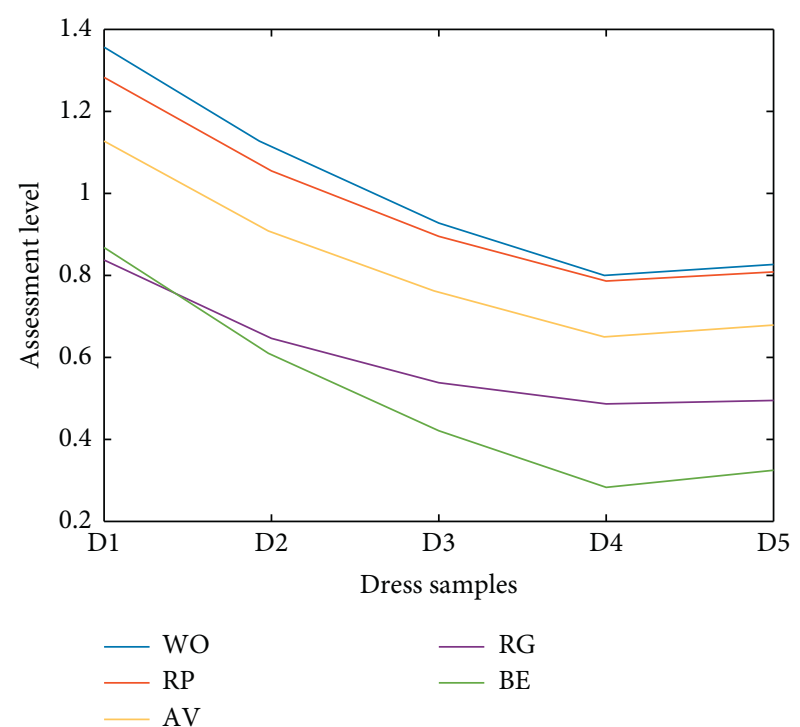

FIGURE 5: Illustration of the same style of clothes made of different fabrics.

evaluation standard can significantly ensure the reliability of the analysis result of the design system by the collaborative fuzzy analytic hierarchy process.

3.5. Garment Modeling Technology. Three-dimensional clothing model is the key to the realization of clothing virtual product design system. Because the $3 \mathrm{D}$ model is close to the real object, the system based on $3 \mathrm{D}$ model provides users with more effective control. For a long time, the research in this field has mainly formed the following modeling 
methods: using points, lines, curves to build a 3D line frame model, using volume units to build a 3D solid model, using point, edge, surf, and other 3D surface modems to create a 3D surface model based on physical 3D modeling, and using the mesh facet method. In addition, there is a neural network survey for free surface reconstruction.

3.5.1. Improved Surface Slice Method. In principle, 3D model is divided into wireframe model, surface model, and solid model. In comparison, wireframe modeling is easy to produce polysemy. Therefore, the surface modeling method is more commonly used. The surface modeling method is divided into bus method and patch method. The generatrix method is based on the idea of line generated surface, mainly based on the relevant principles of computer graphics; the surface patch method is based on the idea of splicing surface, mainly based on the original point set. Both methods have advantages and disadvantages. The bus method needs less original points, mainly through the calculation of some algorithms to get the final model, so the calculation will take a certain time.

(1) Manikin (Human Platform). It is required to be able to express with parameters, in line with the general human body expression habits, such as three surround expression. The key curve can be modified accordingly. For example, change the platform by changing the height and circumference. Figure 6 is the human body shape model.

The idea of modeling is given the points on the key curve of human body (a small number of points can be obtained by means of scanning, etc.), the point set can be obtained by interpolating the related algorithms of graphics, and finally, the three-dimensional model can be formed. Once the platform parameters change, the points on the key curve will be modified accordingly, resulting in the change in point set and the corresponding change in $3 \mathrm{D}$ model. Therefore, the key of human platform modeling is to establish the relationship between the points on the key curve of human body and the parameters such as height and circumference.

(2) Tablet Model. The garment piece has a corresponding two-dimensional template, which requires that the model can be connected with the template. Modeling must be faithful to the relevant attributes of the $2 \mathrm{D}$ template. The modeling process is equivalent to two-dimensional to three-dimensional display of clothing piece, and the threedimensional attributes added to the two-dimensional clothing piece must be consistent with the related attributes of human platform. Figure 7 shows the structure of the garment piece.

The idea of modeling is to construct a middleware virtual shell to support the agricultural production. The relationship between clothing piece and human platform is established through the shell, and finally, the clothing piece model is generated. The original point set of garment model is based on the shell. By adjusting the

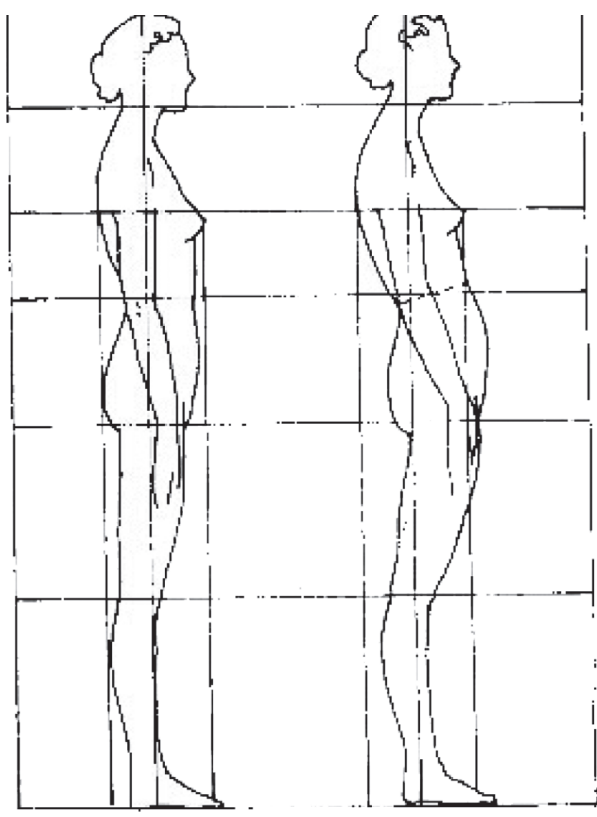

FIGURE 6: Body shape model. Image source: https://image.baidu. com.

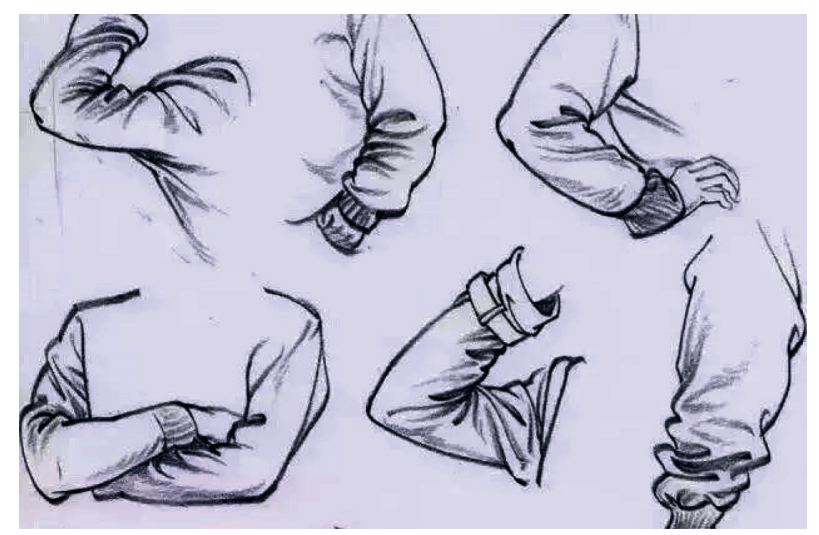

FIGURE 7: Construction of garment piece (image source: https:// image.baidu.com).

relevant algorithm of the shell, the control point set is obtained. Finally, the garment model is generated by the surface slice method.

3.5.2. The Steps of Parametric Graphic Design. The basis of parameter design is to drive the figure by size, that is, to change the size in order to change the figure. Similarly, clothing can generate different sizes according to the change in control parameters suitable for series design. In this article, the parameter design based on the example is divided into the following four steps. Figure 8 shows the flow chart of style parametric drawing:

(1) Extract drawing control parameters. This study analyzes the characteristics of common views of design objects and extracts the key geometric dimensions as 


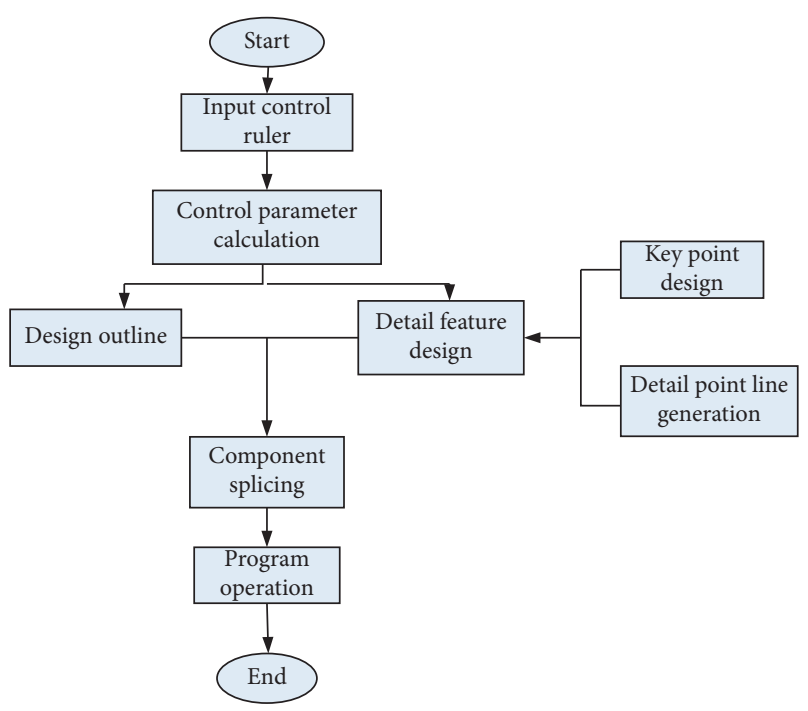

FIgURE 8: Flow chart of style parametric drawing.

the basic drawing parameters. Such as dress length, bust, shoulder width, collar, and other basic parameters.

(2) Establish mathematical relations or equations. Establish the mathematical relationship between the coordinates and basic parameters of all feature points on the graph. The coordinates of each control point can be obtained by extracting the feature points of the drawing for intelligent size control. When new parameters are input, the system can automatically obtain new coordinates.

(3) Programming. Design human-computer interface to input control parameters; design drawing algorithm. The program is the basis of parametric design. The developers compile the corresponding program code according to their own needs to realize the relevant functions of the system.

(4) Program debugging and running. In the process of programming, many mistakes are inevitable. Some may be errors in the program syntax itself. Or, the function of the program is not complete, or it may not achieve the purpose, so the debugging of the program is carried out in the system development process and after development, which is a very important link. The debugging process is mainly to verify and test the accuracy of the determination of the coordinates of the test point, the length of the straight line (line segment), the length of the curve, the selection of the trend parameters, and the mathematical relationship.

3.5.3. Discussion of Results. The three-dimensional clothing model is the key to realize the clothing virtual product design system. Because the 3D model is close to the real object, the system based on the $3 \mathrm{D}$ model provides users with more effective control. As shown in Table 8, we use points, lines, and curves to build a $3 \mathrm{D}$ wireframe model and use volume units to build a $3 \mathrm{D}$ solid model. We draw a combination diagram based on this result, as shown in Figure 9.

Figure 9 shows that the use of points, lines, and curves to build a $3 \mathrm{D}$ wireframe model is also related to the completeness of the designer's design concept and the uniformity of clothing vision. Garment technology is a necessary part of garment modeling. It is a modeling process that stitches the ideas of a designer into a structure by manual or mechanical methods. Its importance cannot be ignored. Through different craftsmanship, it can help realize the many form changes that the designer needs, and it shows the design spirit and connotation.

3.6. Digital Design-3D Printing Technology. The design method of 3D human body scanning proposed for human body modeling starts from $3 \mathrm{D}$ scanning. Especially, in the field of breast, in order to ensure good scanning results, relevant consumers must wear bras and underwear during the scanning process. The scanning results will be further modeled as a digital human-machine model. The general process of using 3D scanning results to model human body in detail. As shown in Figure 10, it is the cheongsam printed in $3 \mathrm{D}$.

In this figure, 3D scanner and software are used to obtain data about body shape. Then, the scanned body shape data are imported into the software to edit and correct the 3D defect mesh objects. Then, the relevant design software can be used to model and simulate the three-dimensional surface shape of the human body. The operation of obtaining 3D scanning license directly is to realize $3 \mathrm{D}$ cutting of 3D human body surface of virtual clothing [26-28]. Detailed body measurements are not required. For people with normal body shape, in the standard body measurement program, the main feature points (such as neck) of the virtual body can be found, and the standard posture can be used for modeling. Based on these symmetrical and easily recognizable main features, the procedure of body measurement becomes very simple. However, due to the body shape is not fixed, for people with scoliosis, many important parts (neck, scapula, etc.) are hidden because they cannot use standard posture. The anthropometric mark of the nonstereotypical body cannot be detected automatically. In order to get a complete three-dimensional shape, a lot of manual adjustment is needed. In this case, the traditional rendering method is closely related to accurate measurement.

\subsection{Sense of Balance in Clothing Produced by the Opposition and Offset of Different Forces}

3.7.1. Application Examples in Clothing Style Modeling. The style has changed the common form of left-right symmetry of the collar shape, combined with a more exaggerated design technique with the vertical cut, so that the entire collar gradually changes from the lapels on the right to the wide lapel on the left, creating a wide and large collar with asymmetric left and right. The results are shown in Table 9. We draw a histogram based on this result, as shown in Figure 11. 
TABLE 8: Clothing modeling data sheet.

\begin{tabular}{|c|c|c|c|c|c|c|}
\hline Dress samples & Point and point & Point and line & Point and surface & Line and line & Line and surface & Surface and surface \\
\hline D1 & 2.15 & 2.33 & 2.29 & 1.72 & 3.12 & 2.71 \\
\hline $\mathrm{D} 2$ & 3.89 & 2.46 & 3.32 & 1.89 & 2.79 & 3.32 \\
\hline D3 & 4.67 & 4.41 & 3.88 & 3.21 & 4.09 & 4.29 \\
\hline D4 & 5.37 & 5.47 & 5.03 & 4.24 & 5.25 & 4.98 \\
\hline D5 & 4.82 & 5.13 & 5.35 & 5.03 & 5.64 & 5.32 \\
\hline
\end{tabular}

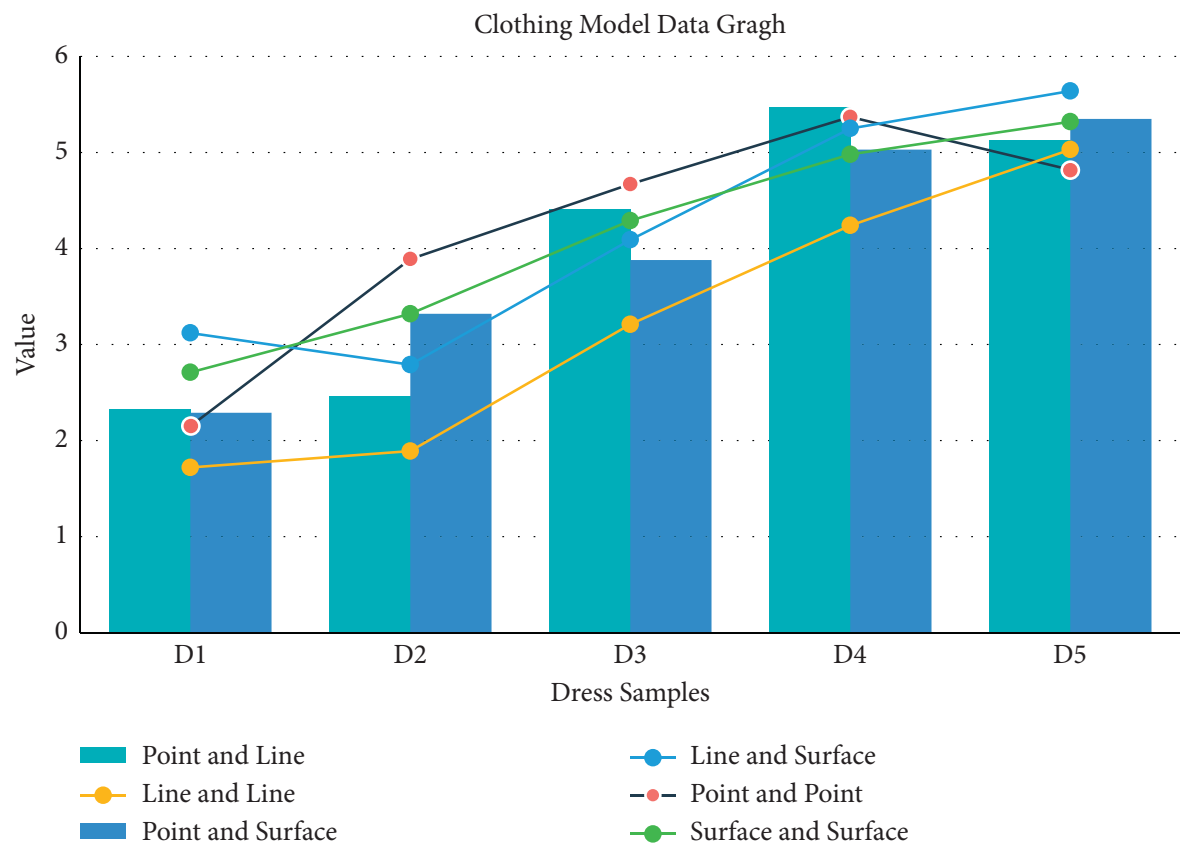

Figure 9: Clothing model data graph.

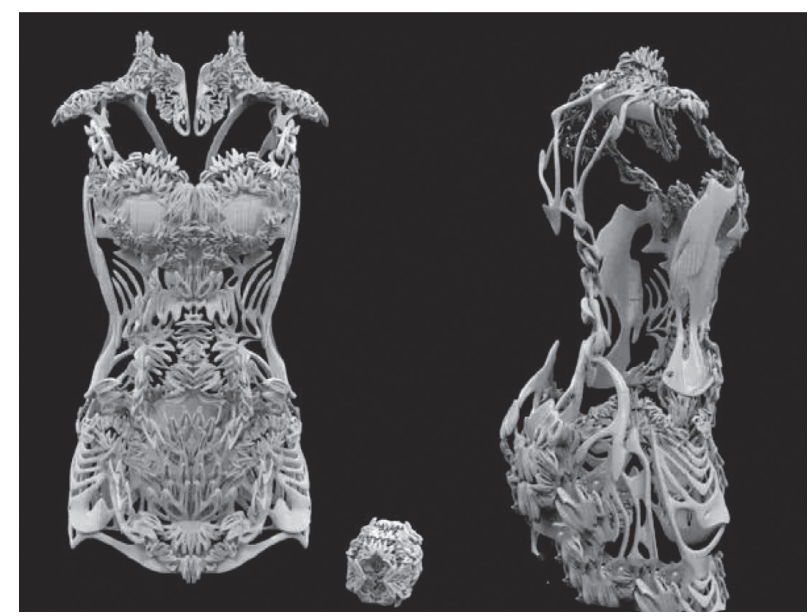

FIGURE 10: Cheongsam printed in 3D (image source: https://image.baidu.com).

TABLE 9: Clothing modeling data sheet.

\begin{tabular}{lccccccc}
\hline Sample & $\begin{array}{c}\text { Extremely more } \\
\text { important }\end{array}$ & $\begin{array}{c}\text { More } \\
\text { important }\end{array}$ & $\begin{array}{c}\text { A little more } \\
\text { important }\end{array}$ & Equal & $\begin{array}{c}\text { A little less } \\
\text { important }\end{array}$ & $\begin{array}{c}\text { Less } \\
\text { important }\end{array}$ & Extremely less important \\
\hline A & 1.45 & 1.91 & 2.13 & 1.07 & 1.87 & 2.49 & 2.18 \\
B & 1.39 & 2.01 & 0.93 & 1.29 & 1 & 0.97 & 1.31 \\
\hline
\end{tabular}


TABle 9: Continued.

\begin{tabular}{lccccccc}
\hline Sample & $\begin{array}{c}\text { Extremely more } \\
\text { important }\end{array}$ & $\begin{array}{c}\text { More } \\
\text { important }\end{array}$ & $\begin{array}{c}\text { A little more } \\
\text { important }\end{array}$ & Equal & $\begin{array}{c}\text { A little less } \\
\text { important }\end{array}$ & $\begin{array}{c}\text { Less } \\
\text { important }\end{array}$ & Extremely less important \\
\hline C & 1.05 & 1.3 & 1.15 & 1.01 & 2.04 & 1.35 & 1.96 \\
D & 1.82 & 2.16 & 2.41 & 1.91 & 1.93 & 2.32 & 2.19 \\
E & 2.41 & 2.9 & 2.84 & 2.89 & 2.3 & 2.41 & 2.67 \\
F & 3.4 & 2.95 & 3.18 & 3.36 & 3.05 & 3.45 & 2.86 \\
P & 0.027 & 0.032 & 0.010 & 0.019 & 0.008 & 0.001 & 0.001 \\
\hline
\end{tabular}

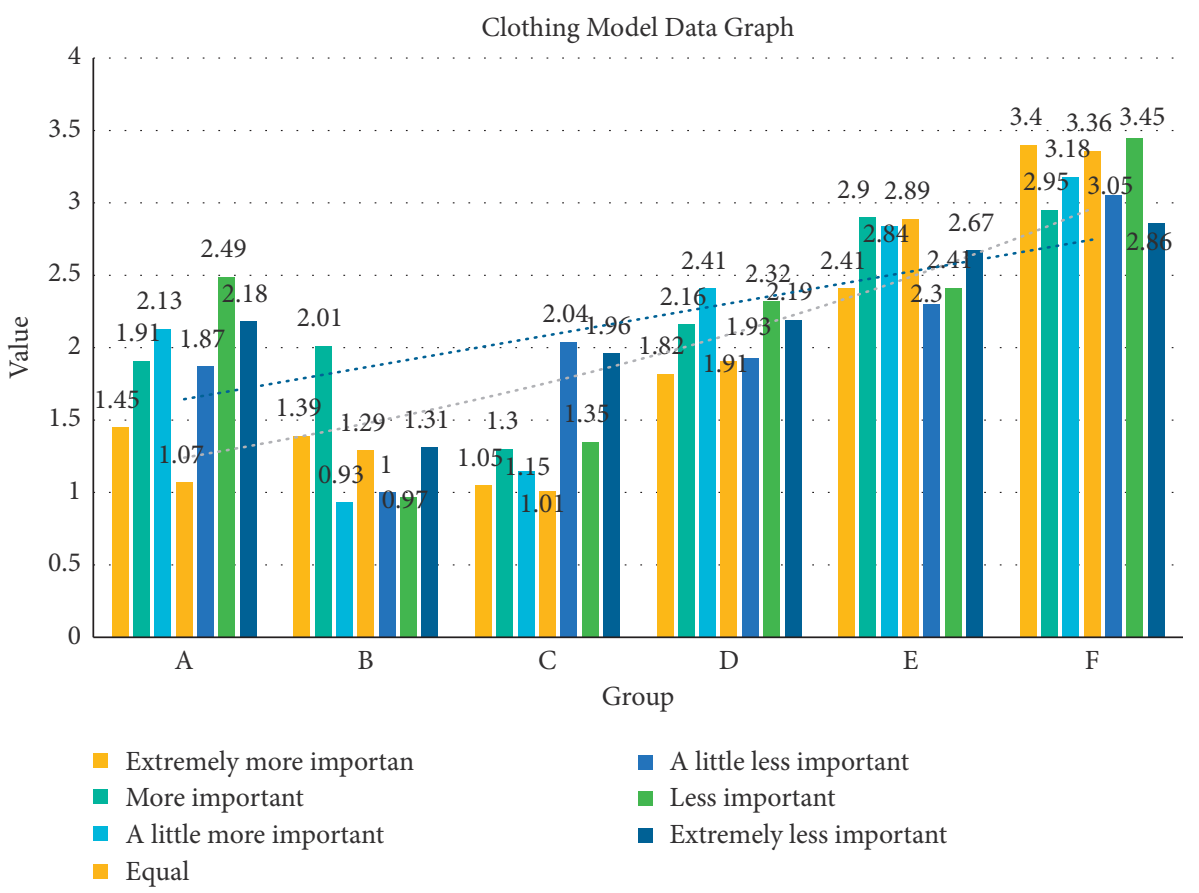

FIGURE 11: Clothing model data graph.

Through the paired sample $T$ test, it can be found that after the experiment, the $P$ value of the relationship between clothing style and artificial intelligence is less than 0.05 . There is a significant difference. This shows that the upper left force formed by the collar part is the same as the direction formed by the lapel part. The force at the lower right produces visual confrontation and offset and finally forms a stable and balanced visual psychological feeling. The specific situation is shown in Figure 11.

3.7.2. Analysis of Application of Color in Clothing. The drape-like color pattern of the front body of the front body that is inclined to the left seam, and the gray of the same color at the interval of the right sleeve forms the force that is inclined to the left and the right, respectively. This group of forces has the same amount but the direction of action. On the contrary, first confront each other and then cancel each other, so that the viewer's visual perception is in a state of balance. The results are shown in Table 10. We draw a combination diagram based on this result, as shown in Figure 12.

Through the paired sample $T$ test, it can be found that after the experiment, the $P$ value of the relationship between clothing color and artificial intelligence is less than 0.05 , and there is a significant difference, which shows that the color purity and brightness changes in the clothing body form a shape of broken lines. The directivity formed by these broken lines is the contradictions and cancellations that produce many forces eventually tend to balance, and the vision is stable and variable. The specific situation is shown in Figure 12.

3.7.3. Application Analysis in Clothing Fabrics. We can use methods such as the matching of different fabrics or the contrast of textures to try to create a sense of balance in the fabric application link of clothing design. The results are shown in Table 11. We draw a bar graph based on this result, as shown in Figure 13.

Through the paired sample $T$ test, it can be found that after the experiment, the $P$ value of the relationship between the clothing fabric and the artificial intelligence is less than 0.05, and there is a significant difference, which shows that the sense of balance in the style is mainly reflected in the hair ball string and striped fur on the clothes. On the decoration, the string of hair balls hanging 
TABle 10: Application data sheet in clothing color.

\begin{tabular}{lccccccc}
\hline Sample & $\begin{array}{c}\text { Extremely more } \\
\text { important }\end{array}$ & $\begin{array}{c}\text { More } \\
\text { important }\end{array}$ & $\begin{array}{c}\text { A little more } \\
\text { important }\end{array}$ & Equal & $\begin{array}{c}\text { A little less } \\
\text { important }\end{array}$ & $\begin{array}{c}\text { Less } \\
\text { important }\end{array}$ & Extremely less important \\
\hline A & 1.87 & 2.46 & 1.19 & 0.95 & 1.67 & 0.77 & 3.72 \\
B & 1.35 & 0.84 & 1.36 & 1.08 & 2.3 & 1.99 & 2.62 \\
C & 1.95 & 2.28 & 1.94 & 1.39 & 2.31 & 2.13 & 2.27 \\
D & 3.14 & 3.48 & 3.4 & 2.32 & 2.66 & 3.68 & 1.97 \\
E & 4.18 & 3.91 & 4.66 & 3.83 & 3.44 & 4.17 & 1.77 \\
F & 5.21 & 5.34 & 5.08 & 4.32 & 4.88 & 5.45 & 1.76 \\
P & 0.005 & 0.008 & 0.010 & 0.010 & 0.004 & 0.005 & 0.005 \\
\hline
\end{tabular}

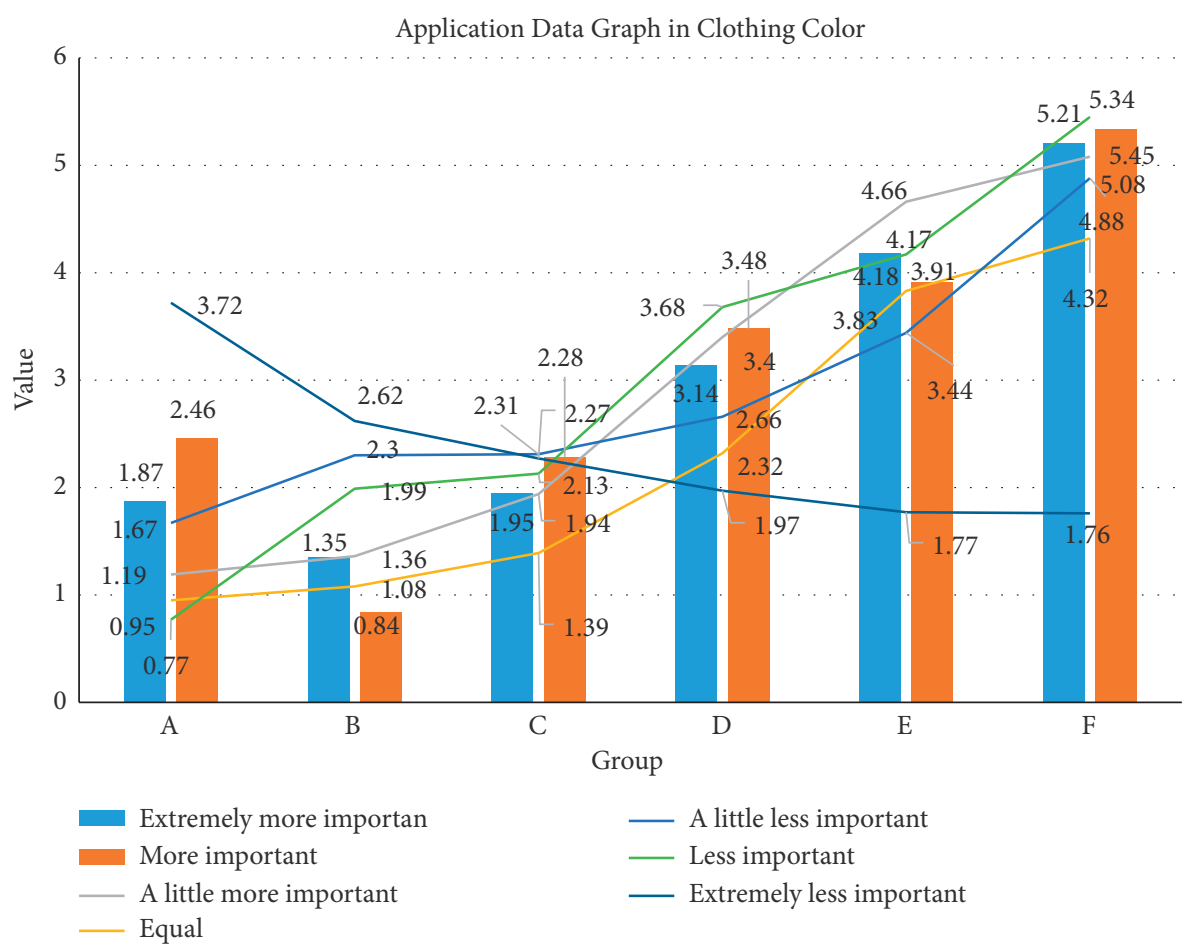

FIgURe 12: Application data graph in clothing color.

Table 11: Application data sheet in apparel fabrics.

\begin{tabular}{lccccccc}
\hline Sample & $\begin{array}{c}\text { Extremely more } \\
\text { important }\end{array}$ & $\begin{array}{c}\text { More } \\
\text { important }\end{array}$ & $\begin{array}{c}\text { A little more } \\
\text { important }\end{array}$ & Equal & $\begin{array}{c}\text { A little less } \\
\text { important }\end{array}$ & $\begin{array}{c}\text { Less } \\
\text { important }\end{array}$ & Extremely less important \\
\hline A & 1.62 & 1.92 & 1.51 & 1.82 & 1.39 & 1.52 & 1.08 \\
B & 2.4 & 1.29 & 0.86 & 1.14 & 2.3 & 1.71 & 1.22 \\
C & 2.42 & 1.96 & 2.43 & 2.35 & 2.07 & 2.32 & 3.89 \\
D & 2.8 & 3.34 & 2.93 & 3 & 3.31 & 4.14 & 3.38 \\
E & 3.92 & 4.35 & 4.12 & 4.01 & 4.13 & 5.25 & 5.28 \\
F & 5.19 & 5.42 & 4.86 & 4.84 & 5.3 & 0.010 & 0.010 \\
P & 0.020 & 0.017 & 0.033 & 0.019 & 0.008 & & \\
\hline
\end{tabular}

down from the neckline are connected with the left and right sides of the body. The specific situation is shown in Figure 13.

3.7.4. Analysis of Embodiment in Garment Craftsmanship. The expression of balance in craftsmanship is mostly achieved using techniques such as modeling three- dimensional folds to achieve visual balance. The results are shown in Table 12. We draw a histogram based on this result, as shown in Figure 14.

Through the paired sample $T$ test, it can be found that after the experiment, the $P$ value of the relationship between clothing technology and artificial intelligence is less than 0.05 , and there is a significant difference, which shows that 


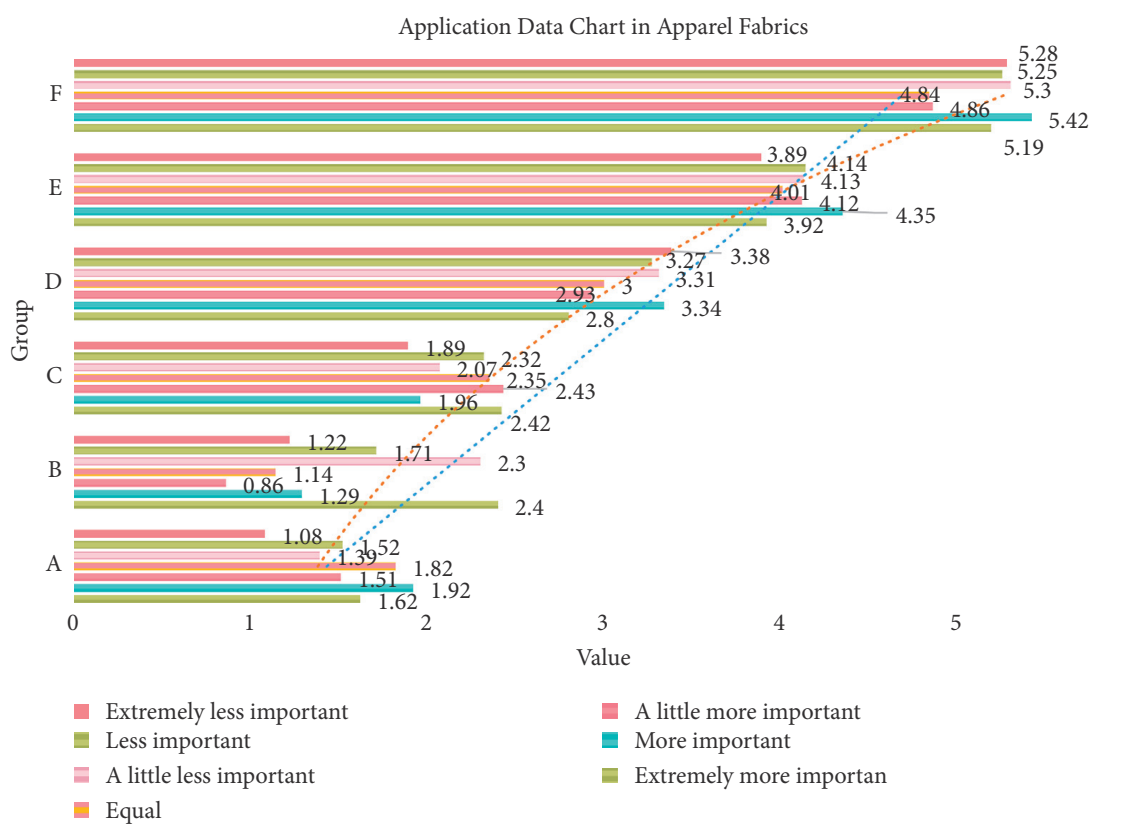

Figure 13: Application data chart in apparel fabrics.

TABLE 12: Reflecting data sheet on clothing technology.

\begin{tabular}{lccccccc}
\hline Sample & $\begin{array}{c}\text { Extremely more } \\
\text { important }\end{array}$ & $\begin{array}{c}\text { More } \\
\text { important }\end{array}$ & $\begin{array}{c}\text { A little more } \\
\text { important }\end{array}$ & Equal & $\begin{array}{c}\text { A little less } \\
\text { important }\end{array}$ & $\begin{array}{c}\text { Less } \\
\text { important }\end{array}$ & Extremely less important \\
\hline A & 2.20 & 2.38 & 3.22 & 4.30 & 3 & 2.57 & 1.85 \\
B & 1.86 & 2.49 & 3.06 & 3.89 & 3.31 & 2.78 & 1.99 \\
C & 1.84 & 2.53 & 2.88 & 4.44 & 3.27 & 2.84 & 1.54 \\
D & 2.28 & 2.64 & 2.81 & 3.98 & 3.38 & 2.30 & 1.77 \\
E & 2.43 & 2.54 & 3.07 & 3.89 & 2.86 & 2.55 & 1.65 \\
F & 2.15 & 2.68 & 3.25 & 3.80 & 3.12 & 2.89 & 1.82 \\
P & 0.001 & 0.001 & 0.001 & 0.001 & 0.001 & 0.001 & 0.001 \\
\hline
\end{tabular}

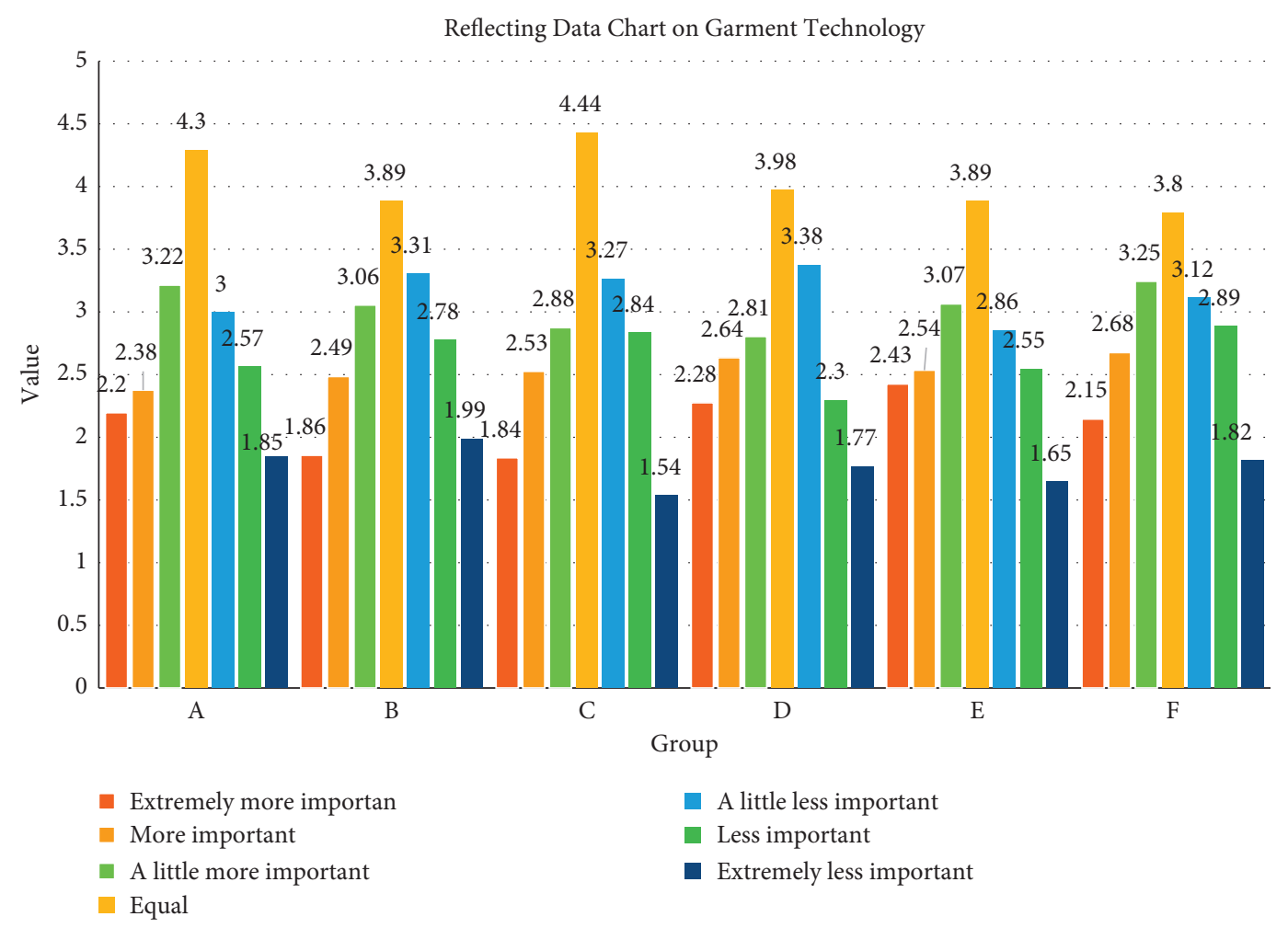

FIGURE 14: Reflecting data chart on garment technology. 
whether it is in sports or dance art, it is a common means to achieve body balance. It is also the habitual balance method in design, and it has strong practicality. The specific situation is shown in Figure 14.

\section{Conclusion}

It is necessary to introduce robots into simple and repetitive jobs and then apply them to all jobs. In this article, various examples are used to verify the effectiveness of the proposed design. On the platform, a group of three-dimensional points are scanned to make a digital model of the human body surface, so that consumers can simulate the shape accompanied by nonstereotyped physical deformation. Next, the feature points of human body are defined. The deformable reinforcement block is modeled on the steel wire frame based on deformation. Compared with the traditional method of making square pattern, the method proposed in this article is simpler and can generate clothing pattern that meets the requirements. This method can be used for making the mascara (top body type) clothing suitable for patients with scoliosis. In addition, the prototype approach of the proposal also solves the problem of comfort caused by clothes.

Firstly, the characteristics and structure of clothing design knowledge are analyzed. The designer's professional knowledge is formalized initially as a rule of language design, so the needs of consumers can be associated with fashion design elements (clothing materials, clothing style, color). The calculation of this system is a series of operations using formal knowledge and case study. In the field of basic design (nonstereotyped) of clothing, compared with the traditional methods of making clothing, the proposed clothing prototype solution starts from personalized clothing, so there will be many kinds of complex operating environments that can avoid when 3D clothing simulation is carried out in the virtual environment.

The suggested design process can be in the process of designers and consumers, ensuring the participation of consumers in the whole design process; the order of design display evaluation adjustment is in the suggested design process. In technology, it is a method and threedimensional virtual experiment realized by virtual threedimensional to two-dimensional design, which enables the proposed mode and principle to elaborate the personalized clothing products to be verified in a very short time; as a knowledge support process, designers can completely extract the personalized concept and principle design from the predefined survey and improve the final. The method can solve the problem of fit and comfort of clothing quickly.

\section{Data Availability}

No data were used to support this study.

\section{Conflicts of Interest}

The authors declare that they have no conflicts of interest.

\section{Acknowledgments}

This work was supported by Research on the construction of course system of costume and costume design specialty under the mode of innovative talents cultivation.

\section{References}

[1] A. Khare and G. Varshneya, "Antecedents to organic cotton clothing purchase behaviour: study on Indian youth," Journal of Fashion Marketing and Management: International Journal, vol. 21, no. 1, pp. 51-69, 2017.

[2] L. Yi, "Fusion mode of artificial intelligence and costume design and its suggestions," Wool Textile Journal, vol. 45, no. 10, pp. 81-85, 2017.

[3] Z. Xulan, Y. Lei, and B. Yu, "Research of clothing design based on low-carbon concept," Wool Textile Journal, vol. 45, no. 8, pp. 58-63, 2017.

[4] L. Shuaishuai, "Research on shanghai-style culture's impact on the development of Chinese domestic luxury brands-from the perspective of \\"Shanghai Tang\!", Journal of Business Administration Research, vol. 6, no. 1, p. 14, 2017.

[5] F. Lin, "Research on a visual graphical user interface design based on artificial intelligence and color semantics," Agro Food Industry Hi-Tech, vol. 28, no. 1, pp. 2127-2130, 2017.

[6] H. Sun, S. P. Chen, and L. P. Xu, "Research on cloud computing modeling based on fusion difference method and selfadaptive threshold segmentation," International Journal of Pattern Recognition and Artificial Intelligence, vol. 32, no. 6, pp. 1859010.1-1859010.15, 2018.

[7] C. Ren, Y. J. Liang, X. J. Lu, and H. B. Yan, "Research on the soil moisture sliding estimation method using the LS-SVM based on multi-satellite fusion," International Journal of Remote Sensing, vol. 40, no. 5-6, pp. 2104-2119, 2019.

[8] Y. Zhang, B. Li, J. Yang, X. Liu, and J. Zhou, "Silicon carbide surface quality prediction based on artificial intelligence methods on multi-sensor fusion detection test platform," Machining Science and Technology, vol. 23, no. 1, pp. 131-152, 2019.

[9] Y. Dai, D. Qiu, Y. Wang, S. Dong, and H.-L. Wang, "Research on computer-aided diagnosis of Alzheimer's disease based on heterogeneous medical data fusion," International Journal of Pattern Recognition and Artificial Intelligence, vol. 33, no. 5, pp. 1957001.1-1957001.17, 2019.

[10] W. U. Xiao, Z. Wang, W. Zhang, and Qian, "Food safety event detection based on multi-feature fusion," Symmetry, vol. 11, no. 10 , p. 1222, 2019.

[11] Y. Wang, L. Ding, Y. Zhang, and K. Luo, "Brain-computer fusion artificial intelligence system based on transfer learning," Journal of Computational Methods in ences and Engineering, vol. 19, no. 2, pp. 247-252, 2019.

[12] Z. Guofeng, F. U. Guixia, G. Mingliang et al., "Multi-scale collaborative coupled metric learning method based on the fusion of class and structure information," Pattern Recognition and Artificial Intelligence, vol. 30, no. 6, pp. 499-508, 2017.

[13] A. H. Harb and A. A. A. A. A. Alsayyid, "Paradigm shift: engineering artificial intelligence and management strategies fusion," International Journal of Regulation and Governance, vol. 4, no. 1, pp. 1-16, 2016.

[14] Y. Z. Zhou, P. X. Li, S. G. Wang et al., "Research progress on big data and intelligent modelling of mineral deposits," Bulletin of Mineralogy, Petrology and Geochemistry, vol. 36, no. 2, pp. 327-331, 2017. 
[15] J. Xue-Bo, S. Ting-Li, K. Jian-Lei, Y.-T. Bai, B.-B. Miao, and C. Dou, "State-of-the-art mobile intelligence: enabling robots to move like humans by estimating mobility with artificial intelligence," Applied Sciences, vol. 8, no. 3, p. 379, 2018.

[16] C. Sung-Goo, "The fourth industrial revolution and changes in the future medical world," Journal of the Korean Medical Association, vol. 60, no. 11, p. 856, 2017.

[17] H. Li, X. Wang, and S. Ding, "Research and development of neural network ensembles: a survey," Artificial Intelligence Review, vol. 49, no. 4, pp. 455-479, 2018.

[18] Y. Chen, C. Hua, and X. Guo, "Face model fitting on video sequences based on incremental virtual active appearance model," Multidimensional Systems and Signal Processing, vol. 28 , no. 1, pp. 1-21, 2017.

[19] S. L. Wang, K. Shafi, T. F. Ng, C. Lokan, and H. A. Abbass, "Contrasting human and computational intelligence based autonomous behaviors in a blue-red simulation environment," IEEE Transactions on Emerging Topics in Computational Intelligence, vol. 1, no. 1, pp. 27-40, 2017.

[20] S. Liu and J. Sheng, "Artists recognition via line shape and ink color distribution of the principal direction for Chinese paintings," Moshi Shibie Yu Rengong Zhineng/pattern Recognition \& Artificial Intelligence, vol. 30, no. 10, pp. 917-927, 2017.

[21] Q. Wu and J. Gu, "Design and research of robot visual servo system based on artificial intelligence," Agro Food Industry Hi-Tech, vol. 28, no. 1, pp. 125-128, 2017.

[22] L. N. Deng and X. F. Yao, "Research on the fusion algorithm of infrared and visible images based on non-subsampled shearlet Transform," Tien Tzu Hsueh Pao/acta Electronica Sinica, vol. 45, no. 12, pp. 2965-2970, 2017.

[23] Y. Lu, Q. Meng, and Y. Cai, "Research on the relationship between R \& D investment and corporate value of "unicorn" companies: based on the financial flexibility of artificial intelligence company data," Open Journal of Business and Management, vol. 06, no. 4, pp. 953-962, 2018.

[24] F. M. Castro, M. J. Marin-Jimenez, N. Guil Mata, and R. Muñoz-Salinas, "Fisher motion descriptor for multiview gait recognition," International Journal of Pattern Recognition and Artificial Intelligence, vol. 31, no. 1, pp. 1756002.1-1756002.40, 2017.

[25] M. Fornazarič and U. Toroš, "Relationship between behavioural factors and colour preferences for clothing," Tekstilec, vol. 61, no. 1, pp. 4-14, 2018.

[26] Y. Jiang, H. Song, R. Wang, M. Gu, J. Sun, and L. Sha, "Datacentered runtime verification of wireless medical cyberphysical system," IEEE Transactions on Industrial Informatics, vol. 13, no. 4, pp. 1900-1909, 2017.

[27] S. Sun, M. Kadoch, L. Gong, and B. Rong, "Integrating network function virtualization with SDR and SDN for $4 \mathrm{G} / 5 \mathrm{G}$ networks," IEEE Network, vol. 29, no. 3, pp. 54-59, 201.

[28] L. Fabisiak, "Web service usability analysis based on user preferences," Journal of Organizational and End User Computing, vol. 30, no. 4, pp. 1-13, 2018. 